\title{
Revolatilization of persistent organic pollutants in the Arctic induced by climate change
}

\author{
Jianmin $\mathrm{Ma}^{1 \star}$, Hayley Hung ${ }^{1 \star}$, Chongguo Tian ${ }^{2}$ and Roland Kallenborn ${ }^{3,4}$
}

\begin{abstract}
Persistent organic pollutants (POPs) are organic compounds produced by human activities that are resistant to environmental degradation. They include industrial chemicals, such as polychlorinated biphenyls, and pesticides, such as dichlorodiphenyltrichloroethane. Owing to their persistence in the environment, POPs are transported long distances in the atmosphere, accumulating in regions such as the Arctic, where low temperatures induce their deposition ${ }^{1,2}$. Here the compounds accumulate in wildlife and humans, putting their health at risk ${ }^{1,3,4}$. The concentrations of many POPs have decreased in Arctic air over the past few decades owing to restrictions on their production and use. As the climate warms, however, POPs deposited in sinks such as water and ice are expected to revolatilize into the atmosphere ${ }^{5}$, and there is evidence that this process may have already begun for volatile compounds ${ }^{6}$. Here we show that many POPs, including those with lower volatilities, are being remobilized into the air from repositories in the Arctic region as a result of sea-ice retreat and rising temperatures. We analysed records of the concentrations of POPs in Arctic air since the early 1990s and compared the results with model simulations of the effect of climate change on their atmospheric abundances. Our results indicate that a wide range of POPs have been remobilized into the Arctic atmosphere over the past two decades as a result of climate change, confirming that Arctic warming could undermine global efforts to reduce environmental and human exposure to these toxic chemicals.
\end{abstract}

Most POPs are manufactured for specific purposes owing to certain characteristic properties; for example, polychlorinated biphenyls (PCBs) have been widely used as electrical fluids and plasticizers owing to their excellent dielectric properties, stability and inertness. Once released, POPs partition into air, water, soil, snow/ice and other environmental media according to their physical-chemical properties. As these properties vary with temperature, climate change will affect their fate in the environment and influence observed concentrations and trends.

Surface reservoirs (for example, oceans and soil) become secondary sources of POPs after they are no longer used, reemitting previously deposited chemicals ${ }^{5,7,8}$. Carried primarily by air from southerly sources to the Arctic, POPs may be deposited and their concentrations amplified in the region as a result of the 'cold-trapping' effect ${ }^{2}$. POPs that have accumulated in the cryosphere may be released during ice/snow melt, and those stored in sea water may be volatilized back into the atmosphere when the Arctic Ocean opens ${ }^{6,9}$. Evidence of evasion from the ocean was observed for $\alpha$-hexachlorocyclohexane ( $\alpha-\mathrm{HCH}$, a pesticide) over open water in Hudson Bay and the Beaufort Sea ${ }^{10}$, and an increase in PCB air concentration was measured at the ice edge in the Atlantic Arctic ${ }^{11}$. Most processes leading to POP exchange in the environment respond to changes in air and ocean temperatures. Air-concentration data of POPs monitored across the Arctic have shown good associations with interannual climate variability in the Northern Hemisphere ${ }^{1,12,13}$. Warming trends in the Arctic, well documented in the past two decades ${ }^{14}$, have accelerated Arctic ice retreat and snow melt. It is, therefore, expected that atmospheric concentrations of POPs will increase owing to re-emission from their repositories in Arctic waters, soils, snow/ice and permafrost.

Indeed, increasing trends of some POPs, including hexachlorobenzene ( $\mathrm{HCB})$ and PCBs, were observed in Arctic air in the early- to mid-2000s at the Zeppelin Mountain Air Monitoring Station, Svalbard/Norway $\left(78^{\circ} 55^{\prime} \mathrm{N}, 11^{\circ} 56^{\prime} \mathrm{E}\right)$, and at the Alert station, Canada $\left(82^{\circ} 30^{\prime} \mathrm{N}, 62^{\circ} 20^{\prime} \mathrm{W}\right)$ : potentially the result of revolatilization from the ocean owing to sea-ice retreat ${ }^{6}$. However, most POPs in the Arctic have shown decreasing trends since the early 1990s (refs 6,12,13). A non-parametric Mann-Kendall statistical test ${ }^{15,16}$ reveals statistically significant declining trends at a 95\% confidence level for ten POPs in weekly measured air concentrations recorded at the Zeppelin Station (1993-2009) (Supplementary Methods and Table S1). Similar declining trends were also reported at the Alert Station for $\mathrm{HCH}$ and chlordanes ${ }^{6}$.

Readily observable increasing trends of $\mathrm{HCB}$ and PCBs in Arctic air (potentially due to climate change) can be attributed to their much higher Henry's law constants (Supplementary Table S2; at $25^{\circ} \mathrm{C}, 49 \mathrm{~Pa} \mathrm{~m}^{3} \mathrm{~mol}^{-1}$ for $\mathrm{HCB}$ and ranging from 18-29 $\mathrm{Pa} \mathrm{m}^{3} \mathrm{~mol}^{-1}$ for PCBs, compared with 0.31 and $0.73 \mathrm{~Pa} \mathrm{~m}^{3} \mathrm{~mol}^{-1}$ for $\gamma$ - and $\alpha-\mathrm{HCH}$, respectively), indicating higher tendencies for volatilization from water to air. Declining trends of other POPs may be caused by decreasing emissions following their worldwide ban or regional restrictions ${ }^{17}$ on their production and use. Other factors, for example, the location of sources, atmospheric reaction/degradation processes, their residence times in the atmosphere and surface media, and their pathway for environmental cycling, also contribute to their observed time trends, potentially overwhelming the influence of Arctic warming.

Here we examine the time series of POP air concentrations measured at the Zeppelin and Alert Stations, using statistical correlation analysis to detect evidence of POP revolatilization in the Arctic induced by regional warming. To do so, the overwhelming declining trend of POPs due to factors other than climate change must first be removed to reveal any underlying variations possibly

\footnotetext{
${ }^{1}$ Air Quality Research Division, Environment Canada, 4905 Dufferin Street, Toronto, Ontario M3H 5T4, Canada, ${ }^{2}$ Yantai Institute of Coast Zone Research, CAS, 17 Chunhui Road, Yantai, China, ${ }^{3}$ Norwegian Institute for Air Research, P.O. Box 100, NO-2027 Kjeller, Norway, ${ }^{4}$ Department of Chemistry, Biotechnology and Food Science (IKBM), Norwegian University of Life Sciences (UMB), Christian Magnus Falsen vei, Postbox 5003, NO-1432 Ås, Norway. *e-mail: jianmin.ma@ec.gc.ca; hayley.hung@ec.gc.ca.
} 
a

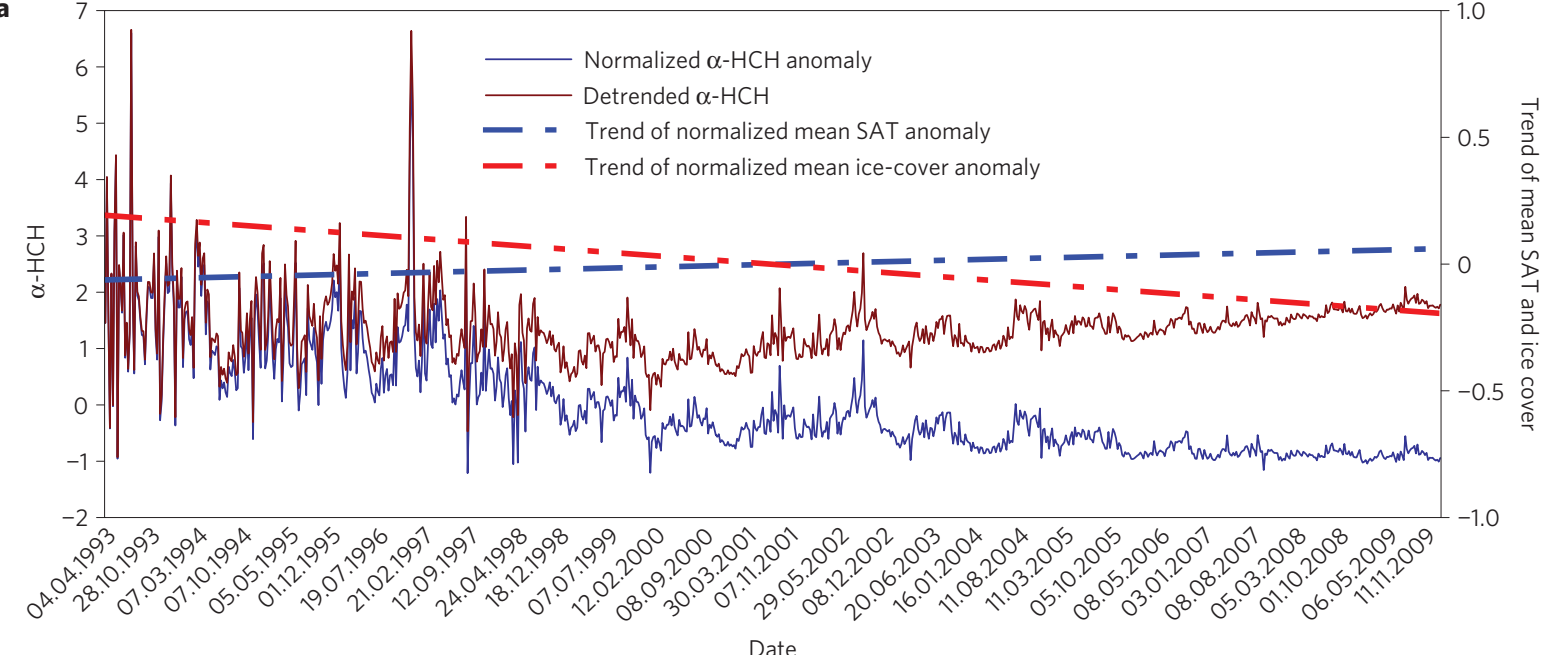

b

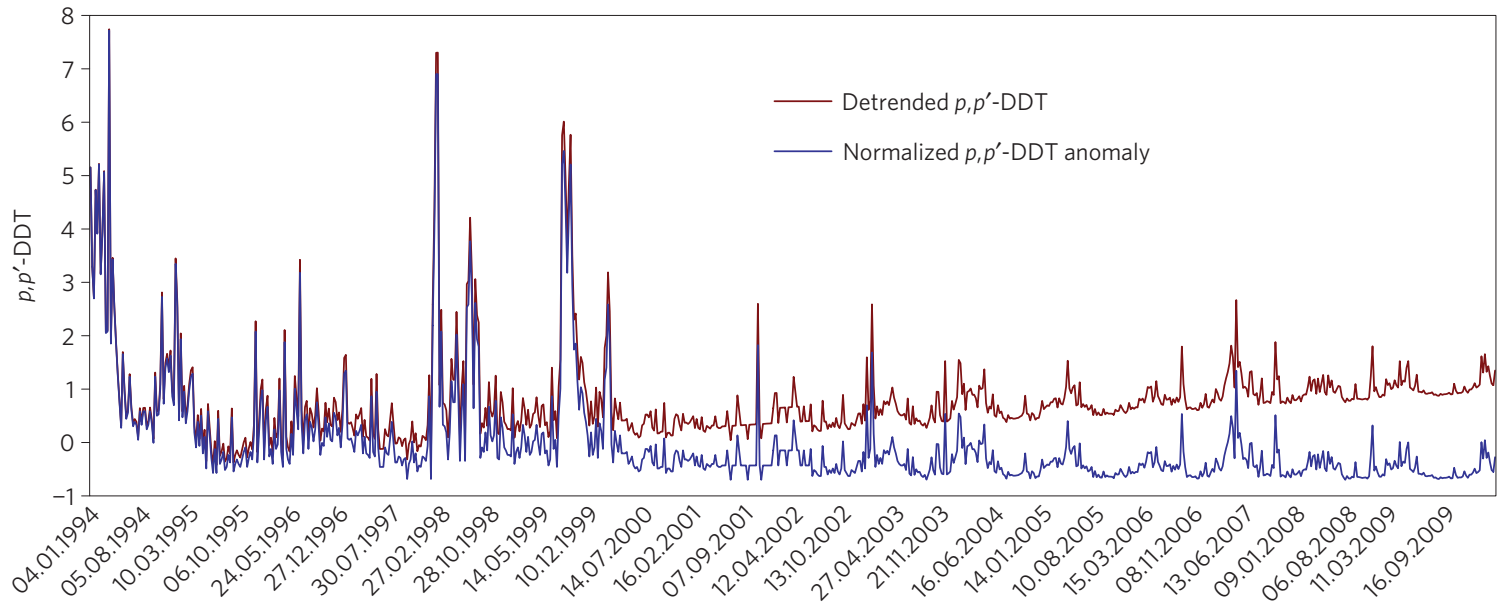

Date

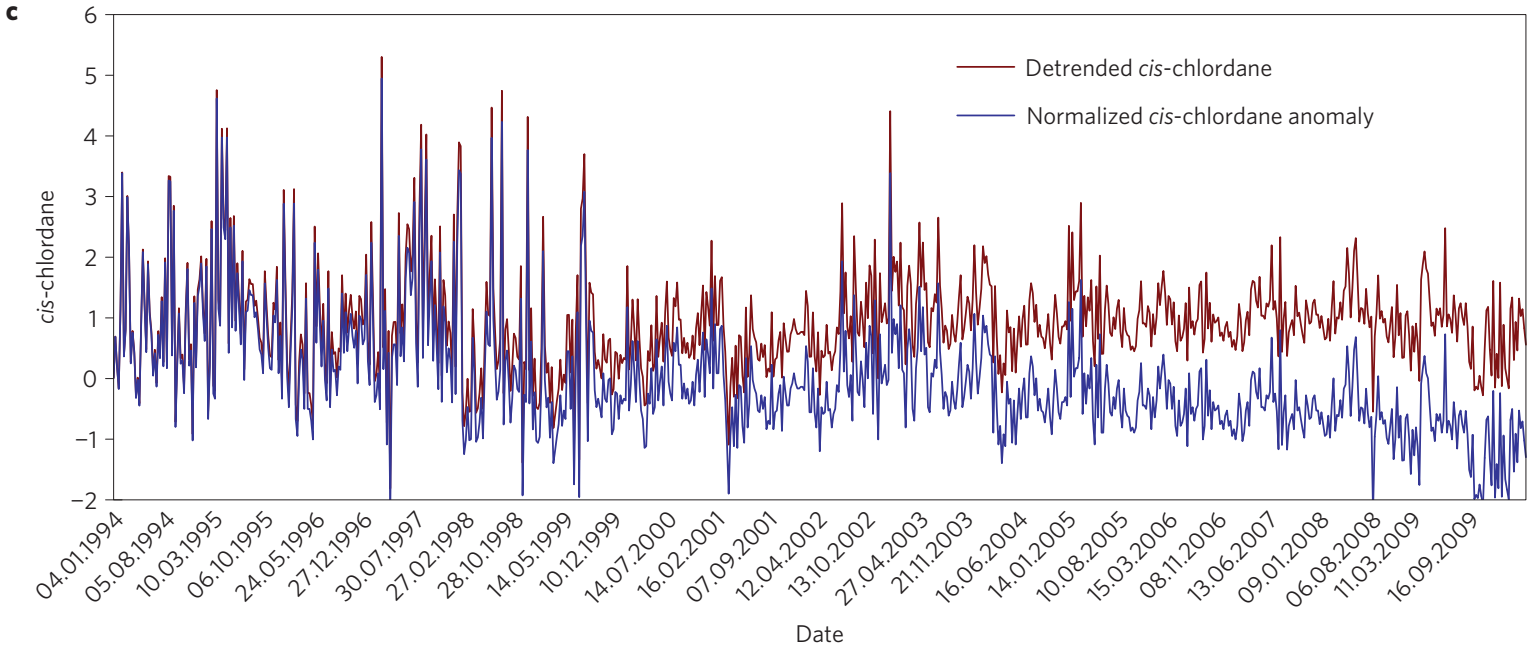

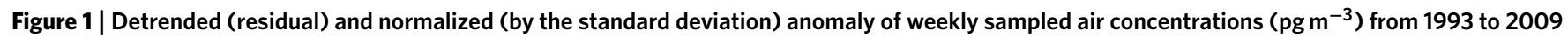
at the Zeppelin Station. a-c, $\alpha-\mathrm{HCH}(\mathbf{a}), p, p^{\prime}$-DDT (b) and cis-chlordane (c) (solid lines) from 1993 to 2009. Linear trends of the normalized mean air-temperature anomaly (blue dashed line) and normalized mean ice cover (red dashed line) over the Arctic are also presented. The air temperature and ice-cover data were collected from the National Oceanic and Atmospheric Administration's National Centers for Environmental Prediction/Department of Energy Reanalysis 2 (ref. 31). The detrended weekly time series of the chemicals are positively correlated with the weekly moving averages of mean air temperature $\left({ }^{\circ} \mathrm{C}\right.$ ) and negatively correlated with the weekly moving averages of mean ice cover (\%) over the Arctic. For instance, there is a statistically significant negative correlation (2000-2009) between detrended $\alpha-\mathrm{HCH}$ and ice cover at $r=-0.38\left(p=1.65 \times 10^{-17}, n=468\right)$. Other correlations between the weekly detrended time series of selected chemicals and SAT/ice cover were not quantified because of a number of missing weekly measurement data of the chemicals. 
related to Arctic warming. This is done by statistical detrending of the observed air-concentration time series at the two sites (see Methods and Supplementary Methods). Figure 1 shows the weekly time series of normalized air-concentration anomalies of $\alpha-\mathrm{HCH}, p, p^{\prime}$-DDT (dichlorodiphenyltrichloroethane) and cischlordane and their respective detrended time series from 1993 to 2009 measured at the Zeppelin Station. The linear trends of weekly moving averages of mean surface air temperature (SAT) and sea-ice-cover anomalies, normalized by their respective standard deviations averaged over the Arctic, are also plotted here. After the overwhelming declining trends are removed, detrended $\alpha-\mathrm{HCH}$, $p, p^{\prime}$-DDT and cis-chlordane show increasing trends corresponding well with increasing Arctic mean SAT and decreasing sea-ice cover (Fig. 1). The association becomes more evident after 2000 when Arctic sea-ice retreat sped up $^{18}$. Detrended air concentrations of $\gamma-\mathrm{HCH}$ (the pesticide lindane) measured at the Zeppelin and Alert Stations are shown in Supplementary Fig. S1. Given that Arctic ice melt occurs mostly in summer and the input of POPs to the Arctic from southerly sources is lowest under the summer atmospheric circulation pattern ${ }^{19}$, local Arctic environmental factors (for example, SAT and sea-ice extent) should be the main influence on changes in POP air concentrations. Indeed, detrended air concentrations of most POPs from 2000 to 2009 are positively and negatively correlated $(|r|>0.5)$, at significance levels of $90 \%$ or more, with summer (June-August) SATs and sea-ice extent from 2000 to 2009, respectively (Supplementary Tables S3 and S4). Further details on correlation analyses are described in Supplementary Methods.

The strong correlations between detrended POP air concentrations and SATs/sea-ice extent indicate that, under Arctic warming, these toxic chemicals probably volatilize from secondary emission sources/reservoirs in water, snow, ice and land across the Arctic, where they have accumulated in the past. These revolatilization processes may contribute to the increasing trend of the detrended POP time series (Fig. 1 and Supplementary Fig. S1). These arguments can be assessed by means of a perturbation model, developed to quantify the extent of climate change influence on POP distribution in the closed air-water and air-soil systems and to interpret the dynamics involved ${ }^{20}$. In the present study, the model has been extended to an air-snow/ice system in the Arctic environment (see Methods). Supplementary Fig. S2 presents perturbed air concentrations $\left(c_{\mathrm{a}}^{\prime}\right)$ of $\alpha-\mathrm{HCH}$ and PCB28 for a period of 50 years under three Arctic-warming scenarios, to examine the sensitivity of POP atmospheric levels to projected Arctic-warming scenarios. These warming scenarios result in marked increases in $c_{\mathrm{a}}^{\prime}$ for both chemicals due to their release from the snowpack. Compared with a mean air concentration $(\bar{c})$ for $\alpha-\mathrm{HCH}$ of $32 \mathrm{pg} \mathrm{m}^{-3}$ over the observation period (the mean concentration used in the perturbation modelling; Supplementary Table S5), a SAT anomaly $\left(T^{\prime}\right)$

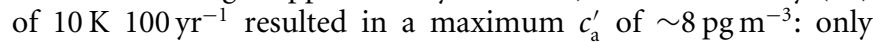
a factor of four lower than the mean concentration, suggesting strong release from contaminated Arctic snowpack ${ }^{21,22}$. In the case of PCB28, which has a larger Henry's law constant than $\alpha-\mathrm{HCH}$, the projected warming leads to lower $c_{\mathrm{a}}^{\prime}$ owing to weaker persistence in air and lower internal energy of phase transfer $\left(\Delta U_{\mathrm{AW}}\right.$; ref. 23) than $\alpha-\mathrm{HCH}$ (Supplementary Table S2), resulting in a smaller increase in Henry's law constant with temperature for PCB28 than for $\alpha-\mathrm{HCH}$ (Supplementary Table S2). Further insight into the changes in the modelled perturbations of POP air concentrations in the air-snow system can be gained from Supplementary Fig. S3, which shows modelled normalized perturbations of summer POP air concentrations in the Arctic from 1993 to 2009.

Snow melt and sea-ice retreat render more open water surfaces across the Arctic Ocean, which is regarded as a major reservoir of POPs in the Arctic ${ }^{24}$. Figure 2a shows modelled annual airconcentration perturbations $\left(c_{\mathrm{a}}^{\prime}\right)$ of $\mathrm{HCH}$ and PCBs from 1991 to 2100 under the Intergovernmental Panel on Climate Change (IPCC) multimodel ensemble averaged annual SAT anomalies over the Arctic using the Special Report on Emissions Scenarios (SRES) A1B emissions scenario (Methods; ref. 25). The perturbed $\alpha-\mathrm{HCH}$ concentration in the atmosphere increases and remains at high values until 2037, decreasing thereafter owing to degradation. The modelled air-concentration perturbation of $\alpha-\mathrm{HCH}$ using the ensemble-averaged IPCC SATs agrees reasonably well with the detrended data from 1999 to 2009, with $r=0.66(p=0.028)$. This enhances our confidence in the prediction of atmospheric POP concentrations under projected twenty-first-century climate change scenarios. PCB congeners 28, 52 and 101 show similar trends. Differing from $\alpha-\mathrm{HCH}$ and these three PCBs, the more hydrophobic PCB153 and more water-soluble $\gamma-\mathrm{HCH}$ show increasing trends throughout the twenty-first century, potentially caused by their ability to stay in environmental sinks (for example, sediment/soil and water) for longer periods of time. Under the simulated SAT over the Arctic, the maximum perturbations of the selected POPs range from $0.7 \%(\gamma-\mathrm{HCH})$ to $92 \%$ (PCB153) from their means over the observational period (Fig. $2 \mathrm{a}$ and Supplementary Table S5). The stronger response of PCB153 to the projected warming agrees with the finding of ref. 23 .

Assuming a uniform spatial distribution of $\alpha-\mathrm{HCH}$ in the Arctic air ${ }^{26}$, the modelled $c_{\mathrm{a}}^{\prime}$ in the Arctic air-water system can be compared with the detrended summer $\alpha-\mathrm{HCH}$ air concentration derived from monitored data at the Zeppelin Station (Fig. 2b). Results show a good agreement between modelled perturbation and detrended time series (1994-2009), with a correlation coefficient of $0.72(p=0.001)$. Such a correlation is also seen in the airsnow system (see Supplementary Information), indicating that the exposure and fate of $\alpha-\mathrm{HCH}$ (and other POPs with similar physicalchemical properties) in the Arctic environment is determined largely by revolatilization from the Arctic Ocean and release from snow/ice under Arctic warming. Figure $2 \mathrm{c}$ illustrates detrended and modelled $c_{\mathrm{a}}^{\prime}$ of $p, p^{\prime}$-DDT averaged over the summers of 1993-2009 subject to the summer $T^{\prime}$ in the air-water system. Measured summer air concentrations of $p, p^{\prime}$-DDT are also presented in the figure (dashed line). The modelled $c_{\mathrm{a}}^{\prime}$ of $p, p^{\prime}$-DDT is correlated with the detrended time series with a correlation coefficient of 0.79 ( $p=0.007$ ) from 2000 to 2009.

Detrended data can also help to identify where in the Arctic the climate perturbation is strongest. Figure 3a,b shows spatial correlations between detrended $\alpha-\mathrm{HCH}$ time series and SATs as well as ice cover (Methods). Positive correlations between $\alpha-\mathrm{HCH}$ and mean SAT, indicating increasing $\alpha-\mathrm{HCH}$ air concentrations with increasing SATs, extend from the East Siberia Sea to the Beaufort Sea. Accordingly, strong negative correlations between $\alpha-\mathrm{HCH}$ and ice coverage also lie over this part of the Arctic Ocean. Another region where $\alpha-\mathrm{HCH}$ air concentrations show significant positive correlations with mean SAT and negative correlations with ice coverage is Greenland. The negative correlation between the ice and $\alpha-\mathrm{HCH}$ air concentrations over the Western Arctic Ocean coincides geographically with high water concentrations of the HCHs measured in the Arctic Ocean during the late 1990s (ref. 27), with water concentrations highest in the central Canadian Archipelago, intermediate in the Beaufort and Chukchi seas and at the North Pole, and lowest in the Greenland Sea and northern Barents Sea. The Zeppelin station is located next to the Eastern Arctic Ocean, which had the lowest water concentrations of $\mathrm{HCH}$ and therefore is not a major source of $\alpha-\mathrm{HCH}$ to air. The atmospheric concentration of $\alpha-\mathrm{HCH}$ at the Zeppelin station is probably correlated with SAT and ice coverage owing to atmospheric mixing with surrounding areas. An atmospheric transport model for POPs-the Canadian Model for Environmental Transport of Organochlorine Pesticides (CanMETOP, Supplementary Methods) ${ }^{19,28,29}$ — has been used to simulate water-air exchange fluxes of $\alpha-\mathrm{HCH}$ over the Arctic Ocean 
a

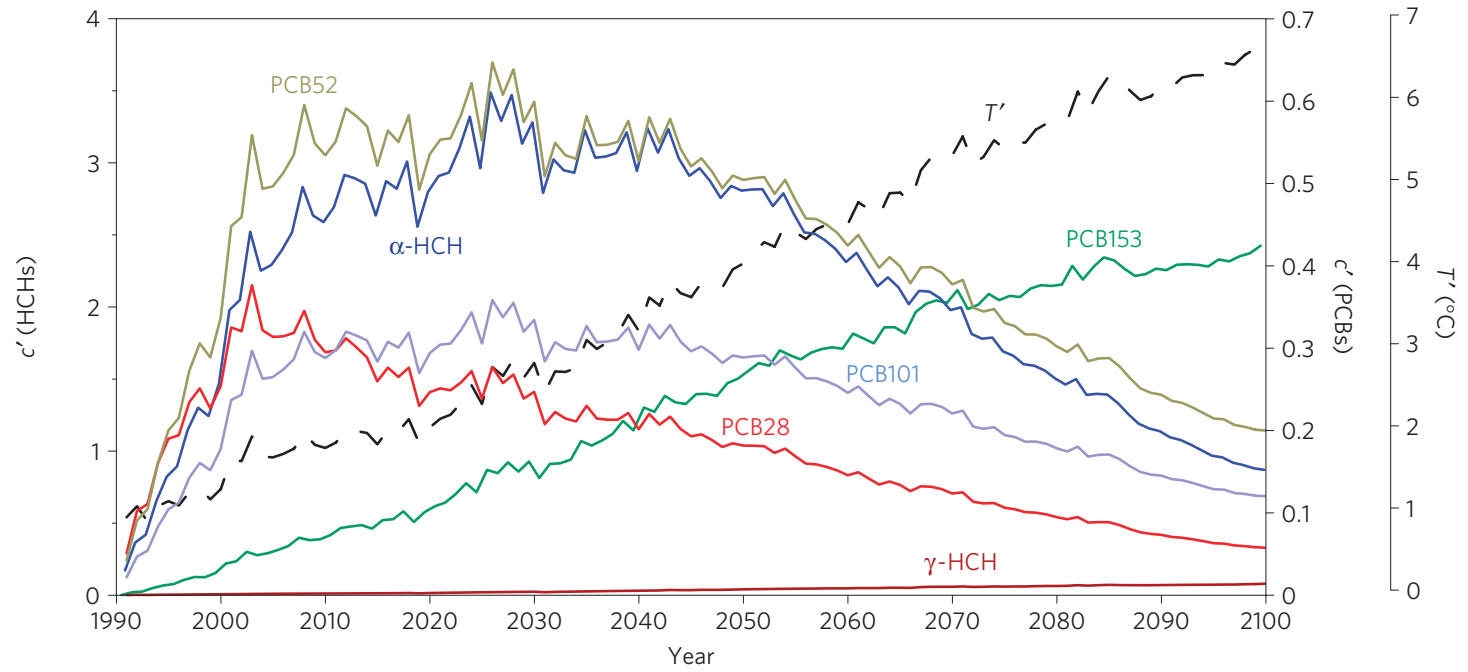

b
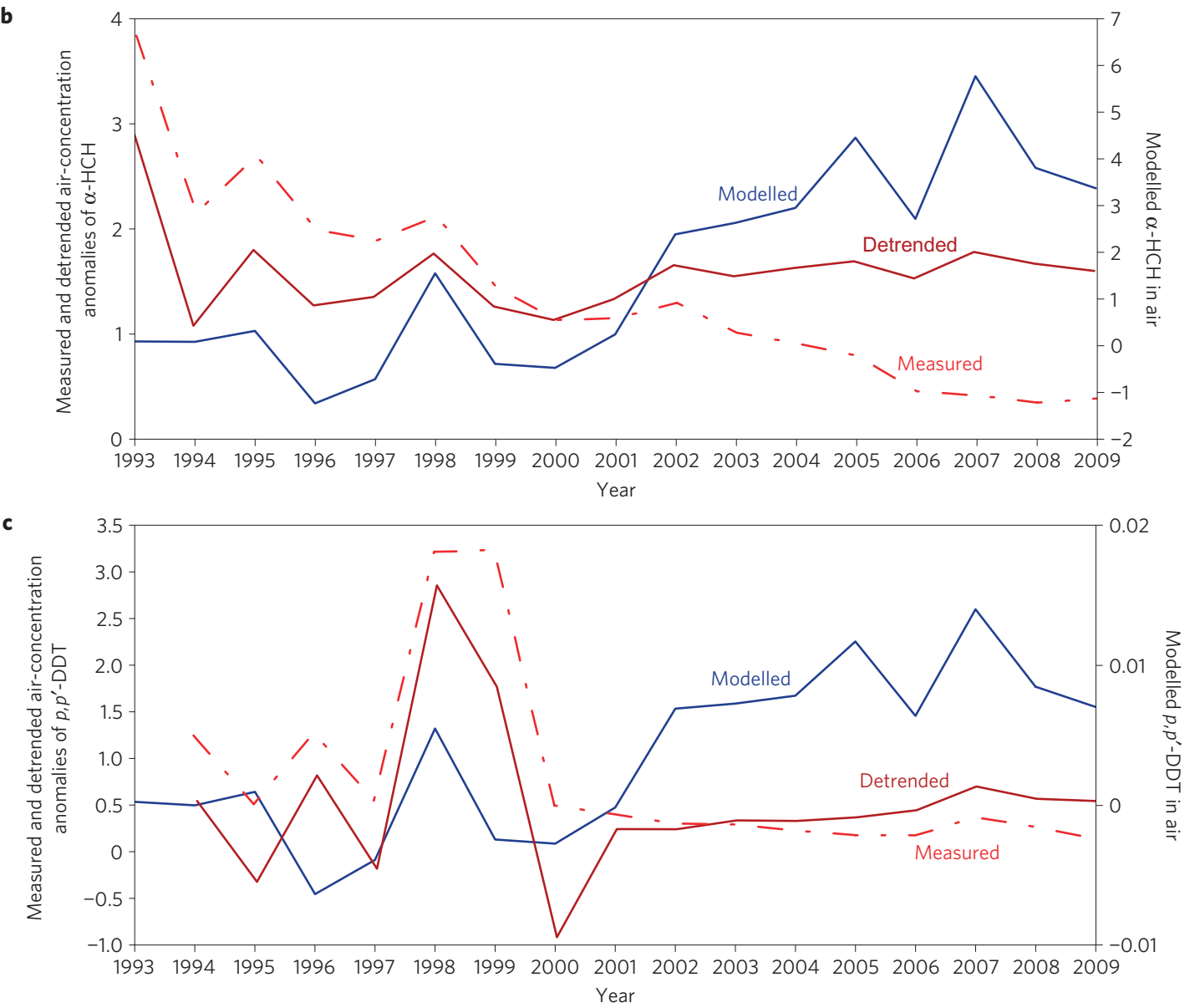

Figure 2 | Comparison of modelled, detrended and measured air concentrations ( $\mathrm{pg} \mathrm{m}^{-3}$ ) of $\mathrm{HCHs}$, PCBs and p, $\mathbf{p}^{\prime}$-DDT. a, Modelled annual air-concentration perturbations of HCHs and PCBs in the closed air-water system from 1991 to 2100 under the IPCC multimodel ensemble average of annual SAT anomalies $\left({ }^{\circ} \mathrm{C}\right)$ over the Arctic under SRES emissions scenario A1B. Annual SAT anomalies $\left(T^{\prime}\right)$ are shown by the black dashed line and scaled on the second right-hand-side $y$ axis; PCBs (scaled on the first right-hand-side $y$ axis) and HCHs (scaled on the left-hand-side $y$ axis) are presented by coloured solid lines. b. Perturbed (in the air-water system), detrended and measured (normalized by standard deviation) summer $\alpha-\mathrm{HCH}$ air concentration at the Zeppelin Station. c, Perturbed (in the air-water system), detrended and measured (normalized by standard deviation) summer $p, p^{\prime}$-DDT air concentrations at the Zeppelin Station. Modelled summer air-concentration perturbations of $\alpha-\mathrm{HCH}$ and $p, p^{\prime}$-DDT used summer air-temperature anomalies $T^{\prime}$ from 1993 to 2009 calculated as the departures from the mean air temperature averaged over 1948-2009 in the Arctic region.

in two modelling scenarios (see Methods). Plotted in Fig. 3c, the modelled flux anomalies agree to some extent with the spatial pattern of the correlation coefficients between $\alpha-\mathrm{HCH}$ and SATs (Fig. 3a). A sink-to-source reversal of $\alpha-\mathrm{HCH}$ in the Arctic Ocean was found in the early 1990s, and its revolatilization from water to air was observed in the Arctic Ocean ${ }^{30}$.

Here, we have demonstrated that Arctic warming affects the fate of POPs in the Arctic environment. The decline of chemicals that 

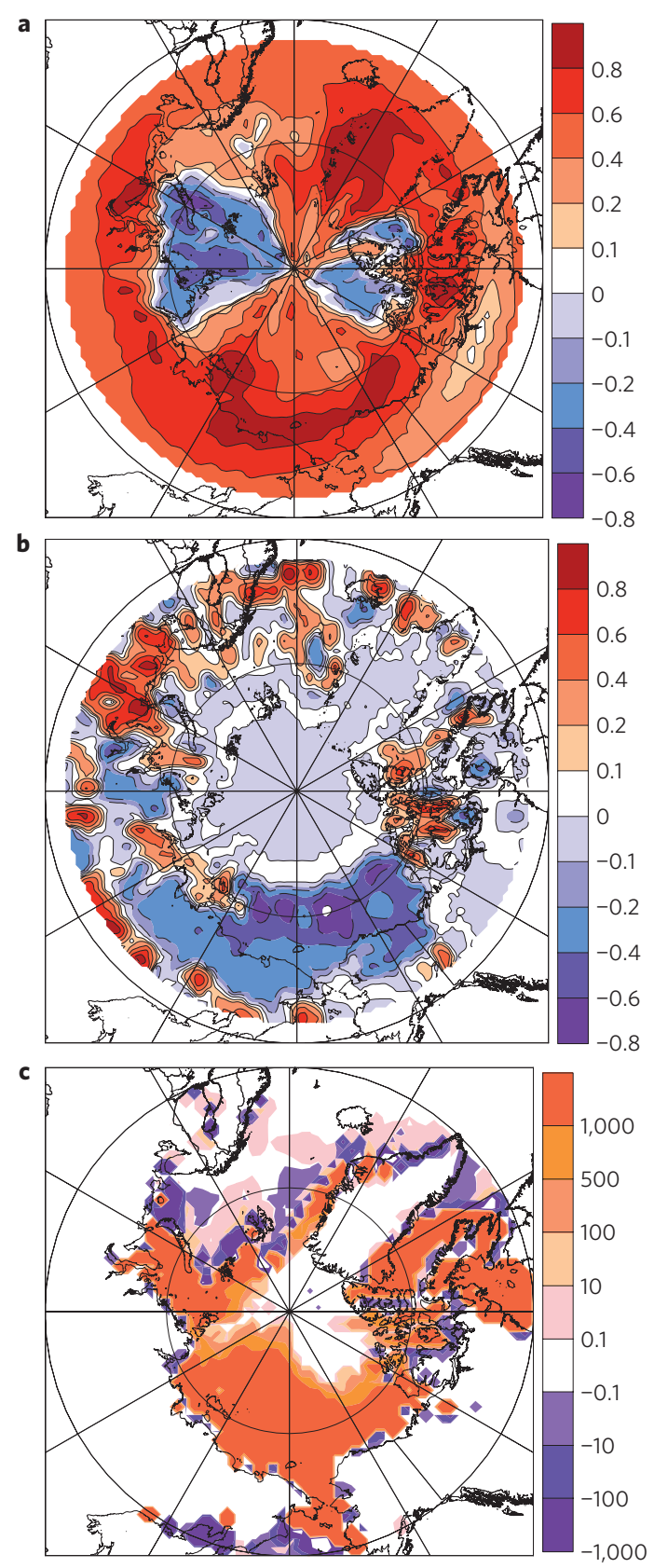

Figure 3 | Correlation coefficients between monitored mean air concentration $\left(\mathrm{pg} \mathrm{m}^{-3}\right.$ ) of $\alpha-\mathrm{HCH}$ at the Zeppelin Station and gridded mean SAT and ice cover across the Arctic, and CanMETOP modelled air-water exchange flux $\left(\mathrm{ng} \mathrm{m}^{-2}\right)$ of $\boldsymbol{\alpha}-\mathrm{HCH}$. a, Spatial-correlation map showing gridded correlation coefficients at $1^{\circ} \times 1^{\circ}$ latitude/longitude between detrended $\alpha-\mathrm{HCH}$ air concentrations at the Zeppelin Station and gridded mean SAT at $1^{\circ} \times 1^{\circ}$ latitude/longitude in the summers from 2000 to 2009 (warm red/orange shades indicate positive correlation). b, The same as a but for correlations between detrended $\alpha-\mathrm{HCH}$ air concentrations at the Zeppelin Station and gridded ice cover (cool blue/purple shades indicate negative correlation). The SAT and ice-cover data used in $\mathbf{a}$ and $\mathbf{b}$ were collected from the National Oceanic and Atmospheric Administration's National Centers for Environmental Prediction/Department of Energy Reanalysis 2 (ref. 31). c, CanMETOP modelled anomaly of $\alpha-\mathrm{HCH}$ air-water exchange fluxes $\left(\mathrm{ng} \mathrm{m}^{-2}\right)$ in 2007 across the Arctic Ocean. Fluxes were calculated by subtracting the fluxes modelled using summer meteorology and ice cover averaged over 1969-2003 from the fluxes modelled using daily summer meteorology and ice cover in 2007. are under global control is expected in the environment. However, with their persistence in sinks such as water, snow/ice and soils, Arctic warming and ice retreat will return them to the Arctic atmosphere, making them once again available for circulation. This will subsequently alter exposure pathways in the biotic environment and related health impacts. This study highlights the importance of improved understanding and awareness of climate influence on the environmental mobility of POPs, which would otherwise undermine global efforts to reduce environmental and human exposure.

\section{Methods}

Statistical detrending, correlation analysis and data. We first removed the overwhelming downward trends to reveal any underlying signals of Arctic warming. Air-concentration anomalies (deviations from the mean over the observation period) were calculated by subtracting the mean concentration of each selected POP from the measured weekly concentrations. The anomalies were then normalized by the standard deviations of all measurements followed by statistical detrending (Supplementary Methods). We detrended all weekly and seasonal time series of air concentrations of POPs monitored at the Zeppelin Station listed in Supplementary Table S1. The rate of increase of the detrended time series of the three substances shown in Fig. 1 is dependent on the magnitude of their respective Mann-Kendall statistic $|Z|$ values (Supplementary Table S1). The spatial correlation analysis (Fig. 3a,b) was conducted by regressing the detrended summer time series of $\alpha-\mathrm{HCH}$ measured at the Zeppelin Station onto $1^{\circ} \times 1^{\circ}$ latitude/longitude gridded mean SAT and ice coverage in the Arctic averaged over summers from 2000 to 2009. All raw data and monitoring information (weekly and seasonal air concentrations) used in the detrending and statistical analysis are freely available on the Arctic Monitoring and Assessment Programme/European Monitoring and Evaluation Programme website at http://tarantula.nilu.no/projects/ccc/emepdata.html.

Perturbation modelling. In the perturbation analysis, concentration $c=\bar{c}+c^{\prime}$, where $\bar{c}$ is the mean or time-averaged concentration of POPs over the observation period and $c^{\prime}$ is the deviation from the mean. The aim is to determine $c^{\prime}$ under the temperature and precipitation perturbation $T^{\prime}\left(T=\bar{T}+T^{\prime}\right)$ and $p^{\prime}\left(p=\bar{p}+p^{\prime}\right)$, where $T$ and $p$ are air temperature and precipitation, respectively, associated with Arctic warming. In the air-snow/ice system, the physical/chemical processes of POPs are perturbed by changes in air temperature, precipitation and snow/ice melt induced by Arctic climate change; the resulting deviations in POP air concentrations from the mean are quantified. Details of perturbation analysis in a closed air-snow/ice system are presented in ref. 20 and Supplementary Methods.

IPCC multimodel ensemble-averaged SATs. The climate model simulated and ensemble-averaged SATs are based on the IPCC Coupled Model Intercomparison Project phase 3 multimodel dataset (available at http://www-pcmdi.llnl.gov/ipcc/about_ipcc.php). The simulations analysed include the integrations of the twentieth-century simulation (IPCC 20C3M) and the twenty-first-century simulation using the IPCC SRES A1B emissions scenario. For each model, the first integration of the 20C3M climates and the corresponding SRES A1B simulation are used ${ }^{25}$.

CanMETOP modelling. Two model scenarios of CanMETOP modelling of air/water exchange fluxes were implemented: (1) using annual mean ice coverage averaged over 1969 to 2003 (the 'norm') and (2) using daily ice coverage in 2007, which shows strong ice melt during the summertime. The difference in fluxes $\left(\mathrm{ng} \mathrm{m}^{-2}\right)$ between the two scenarios is the air-water exchange anomaly for 2007 (that is, deviation of 2007 fluxes from the 'norm'), as presented in Fig. 3c. As there are few spatially resolved measurements of water concentrations of $\alpha-\mathrm{HCH}$ in the Arctic Ocean, a uniformly distributed water concentration $\left(1.5 \mathrm{ngl}^{-1}\right)$ was used as an initial condition in modelling air-water exchange across the surface water of the Arctic Ocean. The water concentrations will be altered subsequently by atmospheric deposition and air-water exchange processes. It must be noted that POP spatial distributions in the Arctic Ocean are not necessarily uniform. If uniformly distributed water concentrations were used as an initial condition, it would only affect modelling results in the early stages of the model run, because the chemical will be subjected to mixing in the atmosphere and the system will tend towards equilibrium in the long term. Details of the CanMETOP are presented in Supplementary Methods.

Received 29 March 2011; accepted 21 June 2011; published online 24 July 2011

\section{References}

1. Macdonald, R. W., Harner, T. \& Fyfe, J. Recent climate change in the Arctic and its impact on contaminant pathways and interpretation of temporal trend data. Sci. Total Environ. 342, 5-86 (2005). 
2. Mackay, D. \& Wania, F. Transport of contaminants to the Arctic: partitioning processes and models. Sci. Total Environ. 160/161, 25-38 (1995).

3. Macdonald, R. W., Mackay, D. \& Hickie, B. Contaminant amplification in the environment: Revealing the fundamental mechanisms. Environ. Sci. Technol. 36, 456A-462A (2002).

4. Kraemer, L. D., Berner, J. E. \& Furgal, C. M. The potential impact of climate on human exposure to contaminants in the Arctic. Int. J. Circumpolar Health 64, 498-508 (2005).

5. Nizzetto, L. et al. Atlantic Ocean surface waters buffer declining atmospheric concentrations of persistent organic pollutants. Environ. Sci. Technol. 44, 6978-6984 (2010).

6. Hung, H. et al. Atmospheric monitoring of organic pollutants in the Arctic under the Arctic Monitoring and Assessment Programme (AMAP): 1993-2006. Sci. Total Environ. 408, 2854-2873 (2010).

7. Zhang, L. \& Lohmann, R. Cycling of PCBs and HCB in the surface ocean-lower atmosphere of the open Pacific. Environ. Sci. Technol. 44, 3832-3838 (2010)

8. Li, Y-F. et al. Polychlorinated biphenyls in global air and surface soil: Distributions, air-soil exchange, and fractionation effect. Environ. Sci. Technol. 44, 2784-2790 (2010).

9. Meyer, T., Lei, Y. D., Muradi, I. \& Wania, F. Organic contaminant release from melting snow, 1. Influence of chemical partitioning. Environ. Sci. Technol. 43, 657-662 (2009).

10. Wong, F. et al. Air-water exchange of anthropogenic and natural organohalogens on International Polar Year (IPY) Expeditions in the Canadian Arctic. Environ. Sci. Technol. 45, 876-881 (2011).

11. Gioia, R. et al. Polychlorinated biphenyls in air and water of the North Atlantic and Arctic Ocean. J. Geophy. Res. Atmos. 113, D19302 (2008).

12. Becker, S. et al. Long-term trends in atmospheric concentrations of $\alpha$ - and $\gamma-\mathrm{HCH}$ in the Arctic provide insight into the effects of legislation and climatic fluctuations on contaminants levels. Atmos. Environ. 42, 8225-8233 (2008)

13. Hung, H. et al. Temporal and spatial variabilities of atmospheric polychlorinated biphenyls (PCBs), organochlorine (OC) pesticides and polycyclic aromatic hydrocarbons (PAHs) in the Canadian Arctic: Results from a decade of monitoring. Sci. Total Environ. 342, 119-144 (2006).

14. Steele, M., Ermold, W. \& Zhang, J. Arctic Ocean surface warming trends over the past 100 years. Geophys. Res. Lett. 35, L02614 (2008)

15. Yue, S. \& Wang, C. Y. Regional streamflow trend detection with consideration of both temporal and spatial correlation. Int. J. Climatol. 22, 933-946 (2002).

16. Gao, H., Ma, J., Cao, Z., Dove, A. \& Zhang, L. Trend and climate signals in seasonal air concentration of organochlorine pesticides over the Great Lakes. J. Geophys. Res. 115, D15307 (2010).

17. Li, Y. F. \& Bidleman, T. F. Correlation between global emissions of $\alpha$-hexachlorocyclohexane and its concentrations in the arctic air. J. Environ. Inform. 1, 52-57 (2003).

18. Stroeve, J., Holland, M. M., Meir, W., Scambos, T. \& Serreze, M. Arctic sea ice decline: Faster than forecast. Geophys. Res. Lett. 34, L09501 (2007).

19. Zhang, L., Ma, J., Venkatesh, S., Li, Y. F. \& Cheung, P. Modeling evidence of episodic intercontinental long-range transport of lindane. Environ. Sci. Technol. 42, 8791-8797 (2008).

20. Ma, J. \& Cao, Z. Quantifying the perturbations of persistent organic pollutant induced by climate change. Environ. Sci. Technol. 44, 8567-8573 (2010).
21. Hansen, K. M., Halsall, C. J. \& Christensen, J. H. A dynamic model to study the exchange of gas-phase persistent organic pollutants between air and a seasonal snowpack. Environ. Sci. Technol. 40, 2644-2652 (2006).

22. Meyer, T. \& Wania, F. Organic contaminant amplification during snowmelt. Water Res. 42, 1847-1865 (2008).

23. Lamon, L. et al. Modeling the global levels and distribution of polychlorinated biphenyls in air under a climate change scenario. Environ. Sci. Technol. 43, 5818-5824 (2009).

24. Arctic Monitoring and Assessment Programme Arctic Pollution 2009 (AMAP, 2009); available at http://www.amap.no.83.

25. Pachauri, R. \& Reisinger, A. in IPCC Climate Change 2007: Synthesis Report (Cambridge Univ. Press, 2007); available at http://www.ipcc.ch/publications and_data/publications_and_data_reports.shtml.

26. Su, Y. et al. Spatial and seasonal variations of hexachlorocyclohexanes (HCHs) and hexachlorobenzene (HCB) in the Arctic atmosphere. Environ. Sci. Technol. 40, 6601-6607 (2006).

27. Bidleman, T. F. et al. Sources, Occurrence, Trends and Pathways in the Physical Environment. Canadian Arctic Contaminants Assessment Report II (Northern Contaminants Program 2004); available at http://www.ainc-inac.gc.ca/nth/ct/ncp/pubs/phy/phy-eng.asp.

28. Zhang, Y., Tao, S., Shen, H. \& Ma, J. Inhalation exposure to ambient polycyclic aromatic hydrocarbons and lung cancer risk of Chinese population. Proc. Natl Acad. Sci. USA 106, 21063-21067 (2009).

29. Ma, J, Daggupaty, S, Harner \& Li, T. Impacts of lindane usage in the Canadian prairies on the Great Lakes ecosystem-1: Coupled atmospheric transport model and modeled concentrations in air and soil. Envion. Sci. Technol. 37, 3774-3781 (2003).

30. Jantunen, L. M. \& Bidleman, T. F. Reversal of the air-water gas exchange direction of hexachlorocyclohexanes in the Bering and Chukchi Seas: 1993 versus 1988. Envion. Sci. Technol. 29, 1081-1089 (1995).

31. Kanamitsu, M. et al. NCEP-DOE AMIP-II Reanalysis (R-2). Bull. Am. Meteor. Soc. 83, 1631-1643 (2002).

\section{Acknowledgements}

This study is funded by the Government of Canada Program for International Polar Year (project of the Intercontinental Atmospheric Transport of Anthropogenic Pollutants to the Arctic). B. Yu provided the IPCC multimodel ensemble-averaged surface air temperature data from 1901 to 2100 and Y. Su compiled the data of physical-chemical properties for the selected POPs. The authors would also like to acknowledge financial support for air measurements conducted at the Zeppelin station from the Norwegian Pollution Control Authorities (Norway) and the Alert station from the Northern Contaminants Program (Indian and Northern Affairs Canada). H.H. would like to thank Canadian Forces Station Alert for supporting the data collection.

\section{Author contributions}

J.M. designed the research; J.M., H.H. and R.K. contributed and analysed data; C.T. carried out modelling and J.M. and H.H. wrote the manuscript.

\section{Additional information}

The authors declare no competing financial interests. Supplementary information accompanies this paper on www.nature.com/natureclimatechange. Reprints and permissions information is available online at http://www.nature.com/reprints Correspondence and requests for materials should be addressed to J.M. or H.H. 